\title{
Isomer Distribution of Perfluorocarboxylates in Human Blood \\ - Potential Correlation to Source
}

\author{
Supporting Information
}

\begin{abstract}
Amila O. De Silva and Scott A. Mabury*
Department of Chemistry, University of Toronto, 80 St. George Street, Toronto, ON Canada M5S 3H6

* Corresponding author phone: (416) 978-1780; fax: (416) 978-1631, e-mail: smabury@chem.utoronto.ca
\end{abstract}

\section{Pages: 6}

Figures: 3

Tables: $\mathbf{3}$ 


\section{Extraction, Derivatization, GC-(NCI) MS Analysis and QA/QC of PFCAs in Human Serum}

\section{Extraction of PFCAs from Human Blood Serum}

All PFCA standard stock solutions and other reagent solutions were made with $18 \mathrm{M} \Omega$ water unless otherwise stated. Extraction was conducted by combining $4 \mathrm{ml}$ human blood serum sample, $10 \mathrm{ng}$ of ${ }^{13} \mathrm{C}_{4}$-PFOA internal standard, $4 \mathrm{ml}$ 0.25M sodium carbonate (ACP, Montreal, PQ, Canada, >99\%), $2 \mathrm{ml}$ 0.5M tetrabutylammonium hydrogen sulfate (Sigma Aldrich, Oakville, ON, Canada, >99\%) (adjusted to pH10 using sodium hydroxide, >95\%, Fisher Scientific, Ottawa, ON, Canada), and $10 \mathrm{ml}$ methyl-tert-butyl ether (MTBE) (VWR International, Mississauga, ON, Canada, >99.98\%). These contents were shaken in a polypropylene centrifuge tube for $10 \mathrm{~min}$. After centrifuging for 5 minutes, the MTBE layer was transferred to a $2^{\text {nd }}$ clean tube and remaining sample was shaken for an additional $10 \mathrm{~min}$ with $10 \mathrm{ml}$ of MTBE.

Following centrifugation for $10 \mathrm{~min}$, the MTBE layer was removed and combined with the 1st MTBE layer. The combined MTBE phase was(31) taken to just dryness with $\mathrm{N}_{2}$ gas (Prepurified grade, BOC Gases, Mississauga, ON, Canada).

\section{PFCA Derivatization in Blood Extracts}

Immediately after drying, the extract was acidified to $\mathrm{pH} 1.0$ using concentrated $\mathrm{HCl}$ (Fisher Scientific, Ottawa, ON, Canada, 36.5\%). To this $0.1 \mathrm{~g}$ of sodium chloride (ACP, >99\%) was added along with $20 \mathrm{ml}$ of ethyl acetate (VWR International, >99.99\%).

Dicyclohexylcarbodimide (DCC) (1 ml of $1 \mathrm{M}$ solution in ethyl acetate) was introduced prior to addition of the derivatizing agent 2,4-difluoroaniline (2,4-DFA) (1 $\mathrm{ml}$ of $1 \mathrm{M}$ solution in ethyl acetate). Both DCC and 2,4-DFA were from Sigma-Aldrich with $>99 \%$ purity. The sample was vortexed for $30 \mathrm{sec}$. to complete the reaction. A series of washes of the organic phase were conducted in the following order $5 \mathrm{ml} 10 \% \mathrm{HCl}, 5 \mathrm{ml}$ aqueous saturated sodium bicarbonate, 5 $\mathrm{ml}$ aqueous saturated sodium chloride (both salts from ACP, >99\%). Washes were shaken with the sample, centrifuged for $5 \mathrm{~min}$., and then aqueous layer was drained off from the organic layer. After final wash, sodium sulfate (ACP, >99\%) was added as a drying agent and the organic layer was concentrated to $2 \mathrm{ml}$. Removal of polar constituents was performed by running the concentrated derivatized extract through a silica $(0.75 \mathrm{~g})$ gel column with elution of the derivatives via $15 \mathrm{ml}$ toluene (1.5\% 2-propanol, $1.5 \% \mathrm{n}$-hexanol). The eluant was concentrated to $0.5 \mathrm{ml}$ using a slow stream of $\mathrm{N}_{2}$ gas. Toluene (99.5\%), 2-propanol (>99\%), and 
1-hexanol (>99\%) were acquired from Caledon Laboratories Ltd. (Georgetown, ON, Canada), Vexchem (Aurora, ON, Canada), and Sigma Aldrich, respectively.

\section{GC-(NCI)MS Parameters for Determination of derivatized PFCAs}

The injector was held at $190^{\circ} \mathrm{C}$ for the duration of each run. Initial oven temperature was kept at $80^{\circ} \mathrm{C}$ for $1.5 \mathrm{~min}$, ramped at $0.7^{\circ} \mathrm{C} / \mathrm{min}$ to $110^{\circ} \mathrm{C}$ and held for $5 \mathrm{~min}$. A $0.7^{\circ} \mathrm{C} / \mathrm{min}$ ramp was applied to reach $140^{\circ} \mathrm{C}$. The final step of the oven program was a $30^{\circ} \mathrm{C} / \mathrm{min}$ ramp to $250^{\circ} \mathrm{C}$ and held for 8.00 minutes. Helium was used as the carrier gas with $1.1 \mathrm{ml} / \mathrm{min}$ flow rate. At the detector, the transfer line was held at $250^{\circ} \mathrm{C}$, ion source and quadrupole both at $150^{\circ} \mathrm{C}$.

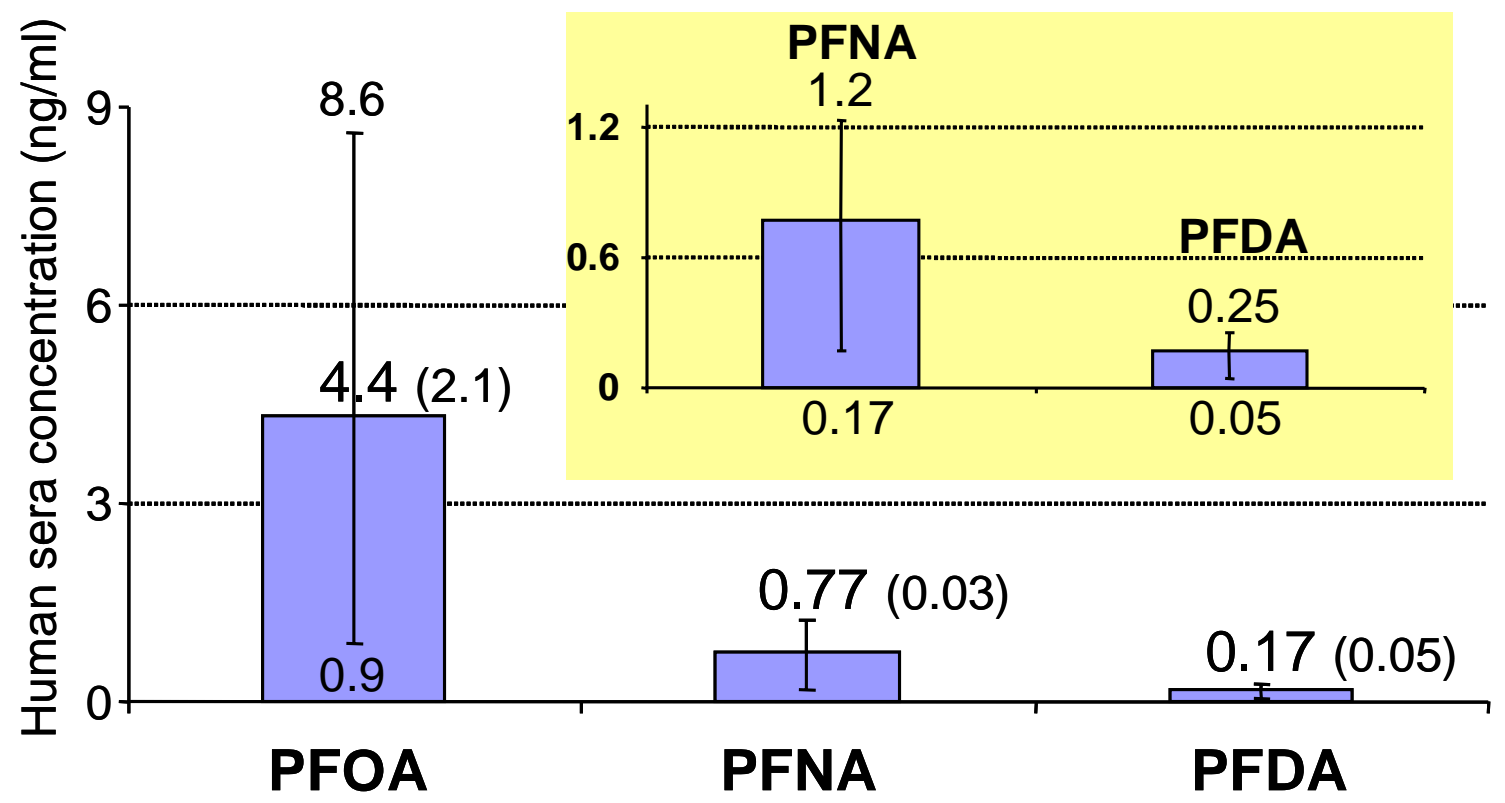

Figure S1. Linear PFCA concentrations in 16 pooled human blood serum samples. Mean represented by columns, standard deviation is in brackets and maximum and minimum indicated by bar limits. Linear PFUnA was detected in 2 samples at 0.048 and 0.067 ng/ml. PFDoA and PFTrA not observed >LOD in any blood sample. 
Table S1. External Calibration Curve Slope and Correlation Coefficients for Linear PFNA and Isopropyl PFNA using 0.5, 2.0, 20.0, and $40.0 \mathrm{ng}$ standards.

\begin{tabular}{lcc}
\hline & $\begin{array}{c}\text { Slope in linear regression of } \\
\mathrm{x}(\text { PFCA mass in } \mathrm{ng}) \text { and } \mathrm{y} \\
\text { (PFCA peak area })\end{array}$ & $\begin{array}{c}\text { Linearity of calibration curve } \\
\mathrm{R}^{2}\end{array}$ \\
\hline Linear PFNA & $\mathrm{y}=0.0998 \mathrm{x}$ & 0.9995 \\
Branched Isopropyl PFNA & $\mathrm{y}=0.0984 \mathrm{x}$ & 0.9996 \\
\hline
\end{tabular}

Table S2. Recovery of 7 isomers of $10 \mathrm{ng}$ ECF PFOA from $4 \mathrm{ml}$ Aldrich human serum matrix $(\mathrm{N}=3)$.

\begin{tabular}{ccc}
\hline Isomer & Average Recovery (\%) & Standard dev. \\
\hline Linear & 98.0 & 3.5 \\
1 & 91.3 & 12.9 \\
2 & 72.1 & 8.9 \\
3 & 89.2 & 4.3 \\
4 & 73.4 & 10.2 \\
5 & 102.3 & 5.5 \\
6 & 97.1 & 5.4 \\
7 & 82.2 & 7.1 \\
8 & 84.0 & 7.7 \\
\hline
\end{tabular}

Table S3. Recovery of $0.76 \mathrm{ng} / \mathrm{ml}$ PFNA, $0.20 \mathrm{ng} / \mathrm{ml}$ PFDA, and $0.06 \mathrm{ng} / \mathrm{ml}$ PFUnA in Aldrich human serum matrix $(\mathrm{N}=3)$.

\begin{tabular}{ccc}
\hline Isomer & Average Recovery (\%) & \%RSD \\
\hline Linear PFNA & 115 & 13 \\
Linear PFDA & 107 & 15 \\
Linear PFUnA & 97 & 11 \\
\hline
\end{tabular}




\section{GC-(NCI)MS Chromatograms of PFCA isomers in human blood sera}

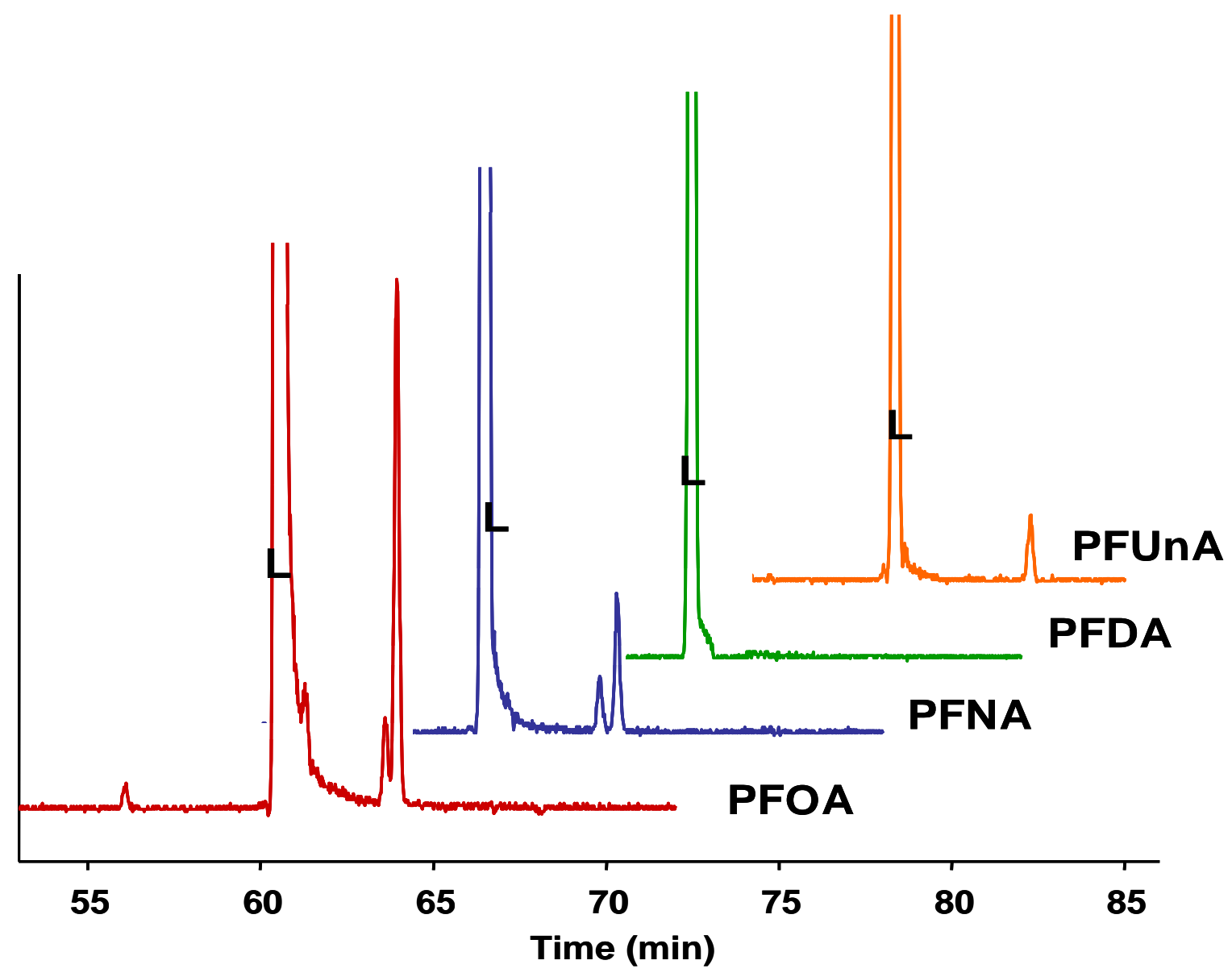

Figure S2. PFCA Isomer profile in pooled human blood serum sample. Peaks labeled with "L" correspond to linear isomer and smaller peaks are ascribed to branched isomers. PFCA levels in this sample were found to be $3.4 \mathrm{ng} / \mathrm{ml}$ PFOA, $0.5 \mathrm{ng} / \mathrm{ml}$ PFNA, $0.2 \mathrm{ng} / \mathrm{ml}$ PFDA, and $0.07 \mathrm{ng} / \mathrm{ml}$ PFUnA. The isomer profile consisted of $1.4 \%$ branched PFOA, $1.9 \%$ branched PFNA, and $2.3 \%$ branched PFUnA. 
Identification of isopropyl branch PFCA isomer.

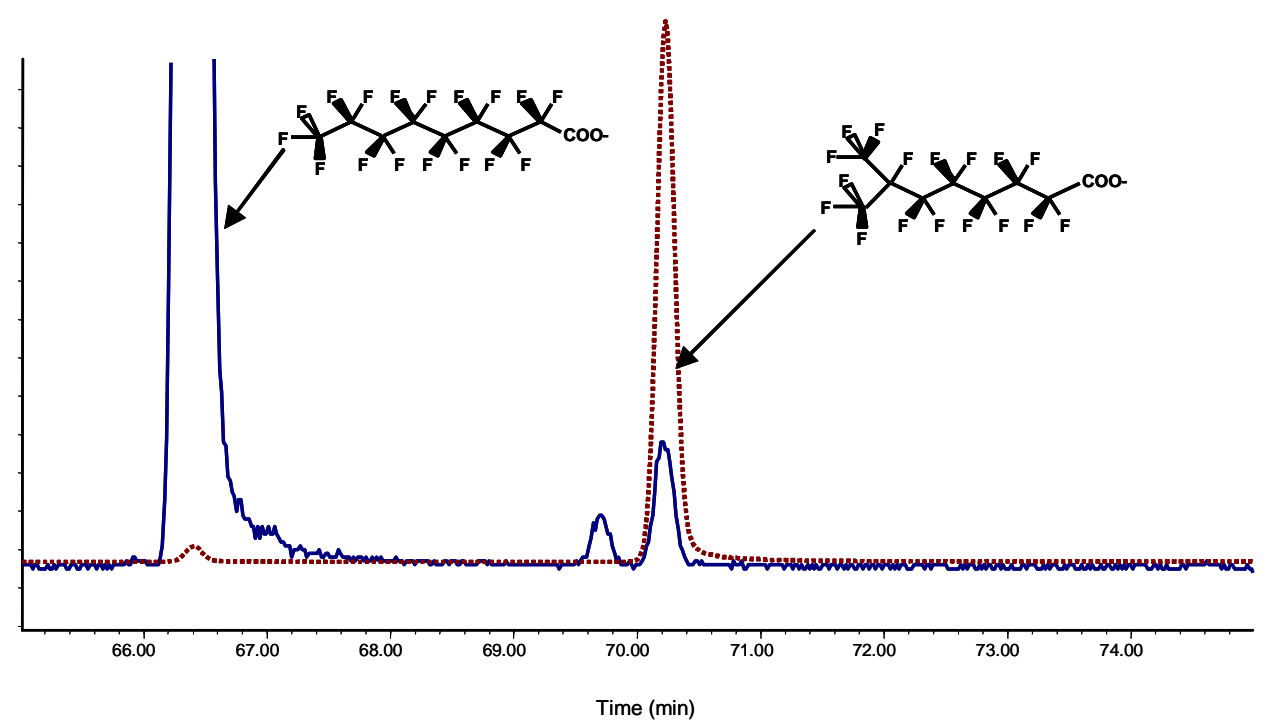

Figure S3. PFNA isomer signature in blood sample (blue solid line) superimposed on isopropyl PFNA branch standard chromatogram (red dashed line). Magnified view of PFNA branched isomers in blood is presented. 